\title{
Research on Operation Cost-Benefits of China High-Speed Railway
}

\author{
Qing Yang \\ School of Economics and Management, East China Jiaotong University, Nanchang, China \\ Email: 576210082@qq.com \\ Received January 2015
}

\begin{abstract}
At Present, to satisfy the demand of passengers travelling convenience, China's High Speed Railway has entered an unprecedented rapid development period. Under this background, research on operation cost-benefits of china high-speed railway is most important and meaningful. The article concludes the following three parts. The first part is to give the definition of research scope. The second part is to give analysis and evaluation on opening and operation cost-benefits. This part is to give a detailed evaluation indexes system and FAHP calculation model; furthermore, to give an example to illustrate the application of evaluation indexes system and FAHP calculation model. The final part is to give effective suggestions and measures to improve cost-benefits of CRH.
\end{abstract}

\section{Keywords}

China High-Speed Railway, Operation Cost-Benefits, Evaluation Indexes, FAHP Calculation Model, Effective Measures

\section{Introduction}

At Present, to satisfy the demand of passengers travelling convenience and saving time, Construction of High-Speed Railway to meet the market demand has become a new trend of railway development in China. According to the <Medium and Long-term Railway Network Planning>, by 2020, our country railway mileage will reach $12,000 \mathrm{Km}$, electrification rate will reach $60 \%$. In which, there will eventually form 30,000 high-speed passenger transportation network with newly built 16,000 Km four vertical and four horizontal passenger railway line and existing line renewal [1]. It can tell us a true fact: China's High Speed Railway has entered an unprecedented rapid development period. Under this background, research on operation cost-benefits of china high-speed railway is most important and meaningful.

The article focuses on comprehensive benefits of high speed railway train with initial letter G, D and C or with speed more than $200 \mathrm{Km} / \mathrm{h}$ [2] (see Table 1-1). Comprehensive benefits include social benefits, economic

Table 1-1. Research scope.

\begin{tabular}{cll}
\hline Range of Trains & Range of Benefits \\
\hline $\begin{array}{c}\text { High speed railway train with initial letter G, D and } \\
\text { C or with speed more than } 200 \mathrm{Km} / \mathrm{h} .\end{array}$ & Social benefits & Economic benefits \\
\hline
\end{tabular}


benefits and market benefit.

\section{Analysis and Evaluation on Operation Cost-Benefits}

\subsection{Definition and Composition of Comprehensive Benefits}

\subsubsection{Social Benefits}

Social benefits are promoting effects to region economic and trade exchanges, tourism development, the personnel flow and material circulation brought by opening of high speed railway train in origin station, intermediate station and terminal station [3]. This index can be reflect and explained by the following three detailed indexes:

\section{1) Number of Train $\mathbf{N}$}

The index is quantity of opening train to transport predict volume of passengers.

\section{2) Number of Passengers Carried $Q_{p}$}

$$
Q_{P}=\sum N_{i} \cdot A_{i} \cdot \bar{\lambda}
$$

$\mathrm{N}_{\mathrm{i}}$ Denotes the quantity of train of type $i$

$A_{i}$ Denotes the train quota of train of type $i \lambda$ Denotes Train Average Attendance Rate

3) Train Average Transport Mileage $l$

$$
l=\frac{\sum n \cdot l}{\sum n}
$$

$\sum n \cdot l$ denotes total mileage of train $\sum n$ denotes total number of opening train

\subsubsection{Economic Benefits}

Economic benefits are earnings equaling to the transportation revenue minus the corresponding costs brought by opening of high speed railway train. It can be explained by the following indexes:

1) Total Transportation Revenue $I_{t}$

It is sum of all types of transportation revenue concluding ticket revenue, package revenue, mail revenue and other revenue. The indexes can be calculated by the following formula:

$$
I_{t}=\sum_{i} N_{i} \cdot A_{i} \cdot \bar{\lambda} \cdot P_{i}
$$

$P_{i}$ Denotes fare rate of train

\section{2) Total Transportation Costs $C_{t}$}

It is sum of all types of transportation costs. The indexes can be calculated simply by the following formula:

$$
C_{t}=c \cdot M \quad M=Q_{p} \cdot \bar{M}
$$

$c$ denotes unit costs of a person kilometer $M I$ denotes average mileage $M$ denotes total volume of passengers

3) Train Average Attendance Rate $\lambda$

$$
\lambda_{k}=\frac{\varepsilon_{k} \cdot l}{\sum_{i} N_{i} \cdot A_{i} \cdot l}
$$

$\varepsilon_{k}$ Denotes traffic density $l$ Denotes length of interval station $\lambda$ Denotes average of $\lambda_{k}$

\subsubsection{Market Benefits}

Market benefits are effects on improvement of railway passenger traffic, increasing of railway competition capacity and strong attractive to potential passenger market [4]. It can be reflected and explained by two types of indexes as follows:

1) Service Quality Index It can be divided the following three types:

(1)Degree of Convenience Index It is gotten by the experts grading score.

(2)Degree of Comfort Index It is also gotten by the experts grading score. 
(3)Departure Frequency Index It is the percentage of opening train numbers accounts for total train number. 2) Market Competition Index It can be divided the following three types:

(1)Available Type of Train Index It is total type available for passengers to choose.

(2)Average Service Frequency Index It is train number allowing to chosen by passengers.

(3)Train Average Speed It is average speed of opening train which can be gotten by statistics.

\subsection{Establishment of Evaluation Indexes System}

According to the definition and description above-mentioned, a detailed evaluation indexes system of high speed railway is as follows. See Table 2-1.

\subsection{Selection of Calculation Model}

The article takes Fuzzy Analytic Hierarchy Process Method (FAHP) to establish comprehensive calculation model to evaluate the comprehensive benefits of opening CRH. The comprehensive calculation model is as follows [5]. See Formula 2-6, 2-7.

$$
\begin{gathered}
B 2=W \cdot R=\left[W_{1}, W_{2}, W_{3}, \ldots W_{n}\right] \cdot\left[\begin{array}{cccc}
r_{11} & r_{12} & \ldots & r_{15} \\
r_{21} & r_{22} & \ldots & r_{25} \\
\vdots & \vdots & \vdots & \vdots \\
r_{n 1} & r_{n 2} & \ldots & r_{n 5}
\end{array}\right]=\left[\mathrm{b}_{1}, \mathrm{~b}_{2}, \mathrm{~b}_{3}, \mathrm{~b}_{4}, \mathrm{~b}_{5}\right] \\
Z=B \cdot V^{T}=\left[\mathrm{b}_{1}, \mathrm{~b}_{2}, \mathrm{~b}_{3} \cdot \mathrm{b}_{4}, \mathrm{~b}_{5}\right] \cdot\left[\mathrm{V}_{1}, \mathrm{~V}_{2}, \mathrm{~V}_{3}, \mathrm{~V}_{4}, \mathrm{~V}_{5}\right]^{\mathrm{T}}
\end{gathered}
$$

(Formula 2-7)

In the comprehensive calculation model, $\mathrm{W}$ denotes weight vector; $\mathrm{W}_{\mathrm{i}}$ denotes weight of No i evaluation index; $R$ denotes total evaluation matrix of $n$ evaluation indexes; $B$ denotes comprehensive evaluation index matrix; $b_{j}$ denotes membership of level $i$.

\section{Set an Example to Illustrate the Application of Evaluation Indexes and Calcula- tion Model}

According to the FAHP Method and Comprehensive Calculation Model, the detailed five evaluation steps applied in $\mathrm{M}$ train are as follows:

Table 2-1. Detailed evaluation indexes system of high speed railway.

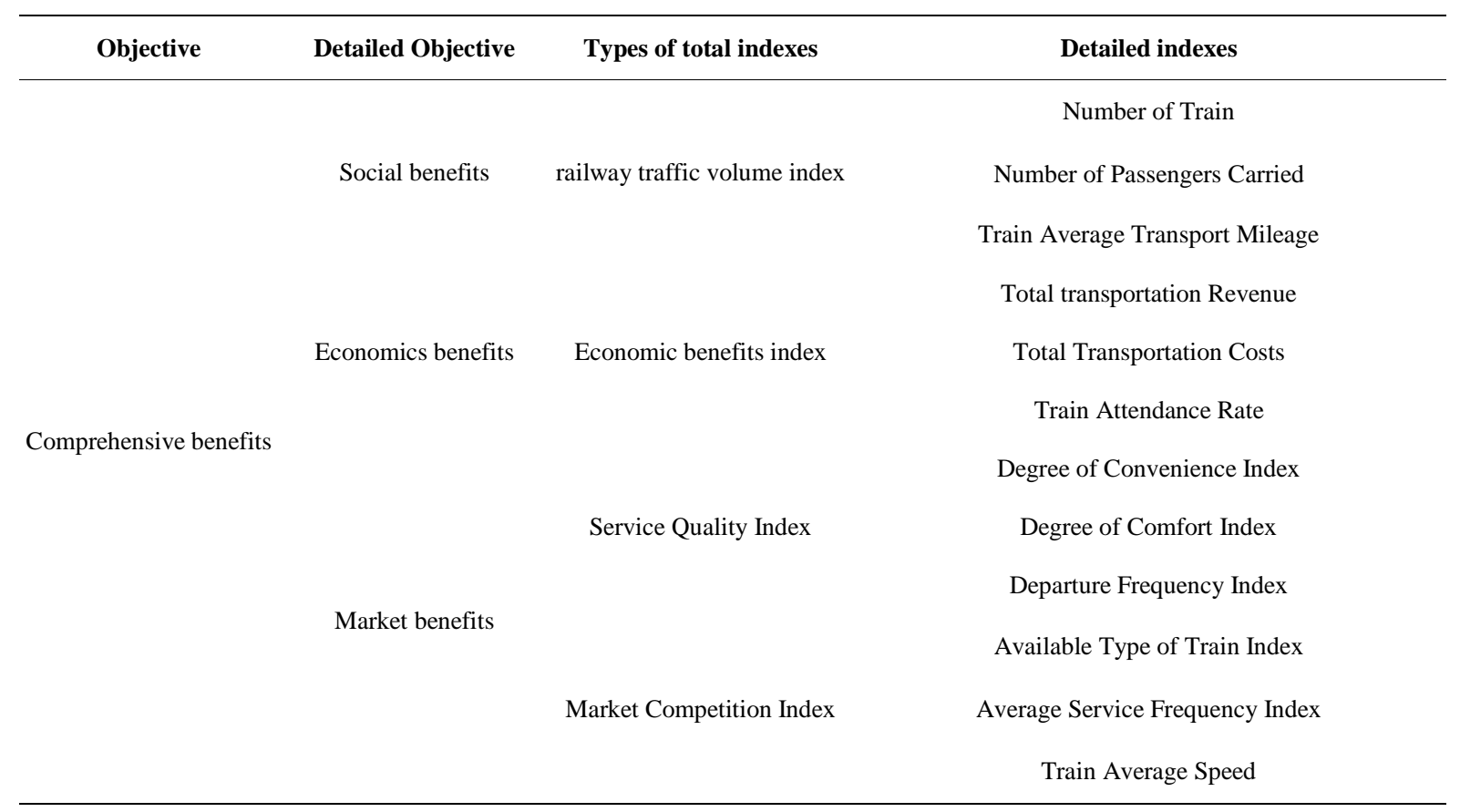




\subsection{Establish Hierarchical Structure Chart (See Figure 3-1)}

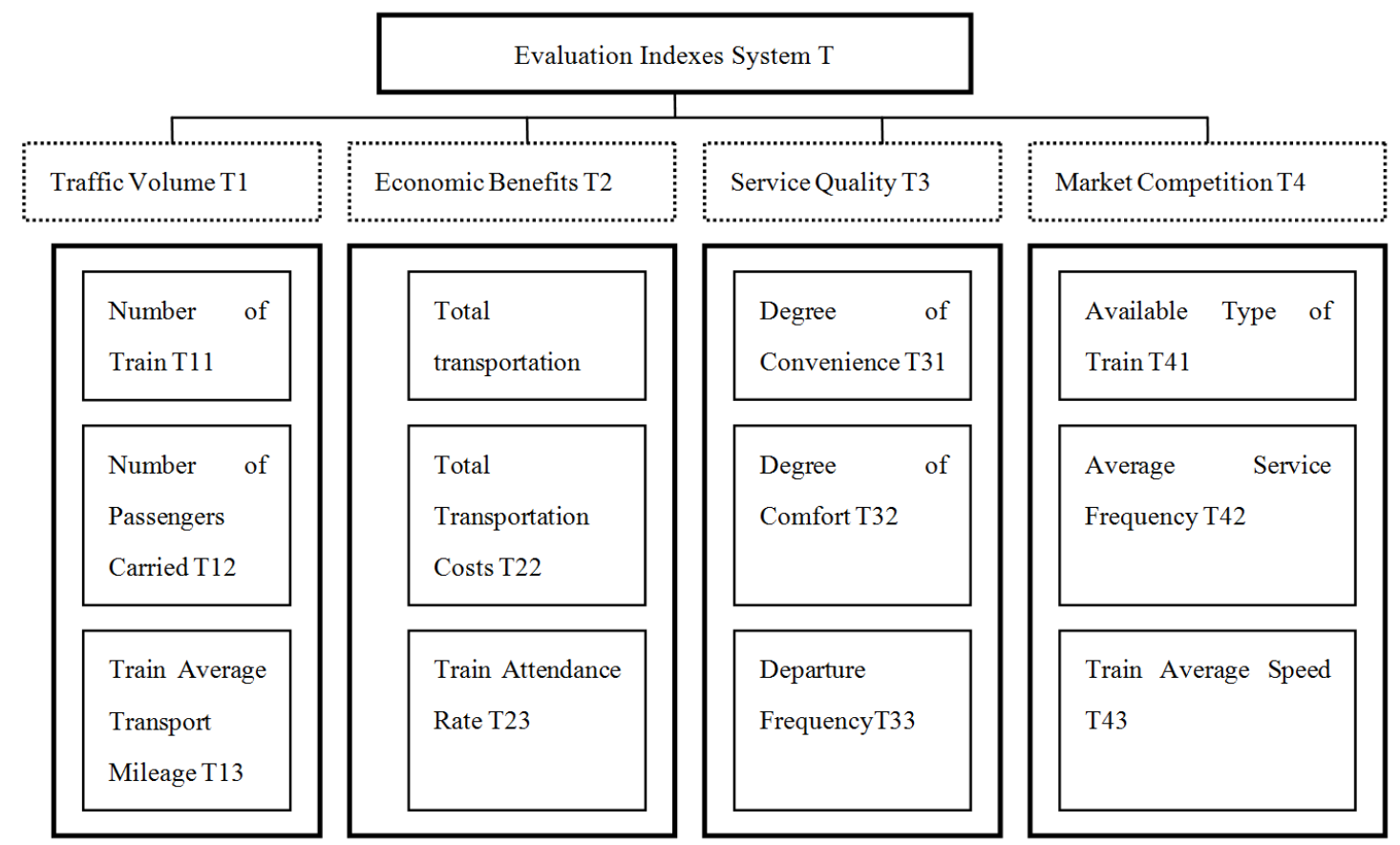

Figure 3-1. Hierarchical structure chart.

\subsection{Establish Fuzzy Complementary Matrix and Weight Calculation}

Table 3-1. Fuzzy Complementary Matrix to determine $T$ and $T_{1}-T_{4}$.

\begin{tabular}{cccccc}
\hline $\mathbf{T}$ & $\mathbf{T}_{\mathbf{1}}$ & $\mathbf{T}_{\mathbf{2}}$ & $\mathbf{T}_{\mathbf{3}}$ & $\mathbf{T}_{\mathbf{4}}$ & $\mathbf{W}$ \\
\hline $\mathrm{T}_{1}$ & 0.5 & 0.2 & 0.3 & 0.4 & 0.175 \\
$\mathrm{~T}_{2}$ & 0.8 & 0.5 & 0.6 & 0.6 & 0.3125 \\
$\mathrm{~T}_{3}$ & 0.7 & 0.4 & 0.5 & 0.6 & 0.275 \\
$\mathrm{~T}_{4}$ & 0.6 & 0.4 & 0.4 & 0.5 & 0.2375 \\
\hline
\end{tabular}

Table 3-2. FCM to determine $T_{1}$ and $T_{11}-T_{13}$.

\begin{tabular}{ccccc}
\hline $\mathbf{T}_{\mathbf{1}}$ & $\mathbf{T}_{\mathbf{1 1}}$ & $\mathbf{T}_{\mathbf{1 2}}$ & $\mathbf{T}_{\mathbf{1 3}}$ & $\mathbf{W}_{\mathbf{1}}$ \\
\hline $\mathrm{T}_{11}$ & 0.5 & 0.3 & 0.6 & 0.321 \\
$\mathrm{~T}_{12}$ & 0.7 & 0.5 & 0.7 & 0.383 \\
$\mathrm{~T}_{13}$ & 0.4 & 0.3 & 0.5 & 0.296 \\
\hline
\end{tabular}

Table 3-3. FCM to determine $T_{2}$ and $T_{21}-T_{23}$.

\begin{tabular}{ccccc}
\hline $\mathbf{T}_{2}$ & $\mathbf{T}_{\mathbf{2 1}}$ & $\mathbf{T}_{22}$ & $\mathbf{T}_{23}$ & $\mathbf{W}_{2}$ \\
\hline $\mathrm{T}_{21}$ & 0.5 & 0.7 & 0.5 & 0.358 \\
$\mathrm{~T}_{22}$ & 0.3 & 0.5 & 0.3 & 0.284 \\
$\mathrm{~T}_{23}$ & 0.5 & 0.7 & 0.5 & 0.358 \\
\hline
\end{tabular}


Table 3-4. FCM to determine $T_{3}$ and $T_{31}-T_{33}$.

\begin{tabular}{ccccc}
\hline $\mathbf{T}_{3}$ & $\mathbf{T}_{31}$ & $\mathbf{T}_{32}$ & $\mathbf{T}_{33}$ & $\mathbf{W}_{3}$ \\
\hline $\mathrm{T}_{31}$ & 0.5 & 04 & 0.6 & 0.333 \\
$\mathrm{~T}_{32}$ & 0.6 & 0.5 & 0.7 & 0.371 \\
$\mathrm{~T}_{33}$ & 0.4 & 0.3 & 0.5 & 0.296 \\
\hline
\end{tabular}

Table 3-5. FCM to determine $T_{4}$ and $T_{41}-T_{43}$.

\begin{tabular}{ccccc}
\hline $\mathbf{T}_{\mathbf{4}}$ & $\mathbf{T}_{\mathbf{4 1}}$ & $\mathbf{T}_{\mathbf{4 2}}$ & $\mathbf{T}_{\mathbf{4 3}}$ & $\mathbf{W}_{\mathbf{4}}$ \\
\hline $\mathrm{T}_{41}$ & 0.5 & 0.3 & 0.4 & 0.296 \\
$\mathrm{~T}_{42}$ & 0.7 & 0.5 & 0.6 & 0.371 \\
$\mathrm{~T}_{43}$ & 0.6 & 0.4 & 0.5 & 0.333 \\
\hline
\end{tabular}

3.3. Determining Membership of Evaluation Index and Judgment Matrix

$$
\begin{aligned}
\mathrm{R}_{1} & =\left[\begin{array}{lllll}
0.324 & 0.394 & 0.282 & 0 & 0 \\
0.335 & 0.404 & 0.261 & 0 & 0 \\
0.328 & 0.417 & 0.255 & 0 & 0
\end{array}\right] \quad \mathrm{R}_{2}=\left[\begin{array}{cccccc}
0.325 & 0.380 & 0.295 & 0 & 0 \\
0.371 & 0.369 & 0.284 & 0.026 & 0 \\
0.302 & 0.378 & 0.320 & 0 & 0
\end{array}\right] \\
\mathrm{R}_{3} & =\left[\begin{array}{llllll}
0.392 & 0.405 & 0.190 & 0.013 & 0 \\
0.294 & 0.375 & 0.331 & 0 & 0 \\
0.351 & 0.402 & 0.247 & 0 & 0
\end{array}\right] \mathrm{R}_{4}=\left[\begin{array}{ccccc}
0.360 & 0.386 & 0.254 & 0 & 0 \\
0.295 & 0.370 & 0.335 & 0 & 0 \\
0.401 & 0.378 & 0.221 & 0 & 0
\end{array}\right]
\end{aligned}
$$

\subsection{Establish Comprehensive Evaluation Model}

$$
\begin{aligned}
& B_{1}=W_{1} \cdot R_{1}=\left[\begin{array}{lll}
0.321 & 0.383 & 0.296
\end{array}\right]\left[\begin{array}{ccccc}
0.324 & 0.394 & 0.282 & 0 & 0 \\
0.335 & 0.404 & 0.261 & 0 & 0 \\
0.328 & 0.417 & 0.255 & 0 & 0
\end{array}\right] \\
& =\left[\begin{array}{lllll}
0.3294 & 0.4046 & 0.2660 & 0 & 0
\end{array}\right] \\
& B_{2}=W_{2} \cdot R_{2}=\left[\begin{array}{lll}
0.358 & 0.283 & 0.358
\end{array}\right]\left[\begin{array}{ccccc}
0.325 & 0.380 & 0.295 & 0 & 0 \\
0.371 & 0.369 & 0.284 & 0.026 & 0 \\
0.302 & 0.378 & 0.320 & 0 & 0
\end{array}\right] \\
& =\left[\begin{array}{lllll}
0.3153 & 0.3758 & 0.3005 & 0.007 & 0
\end{array}\right] \\
& B_{3}=W_{3} \cdot R_{3}=\left[\begin{array}{lll}
0.333 & 0.371 & 0.296
\end{array}\right]\left[\begin{array}{ccccc}
0.392 & 0.405 & 0.190 & 0.013 & 0 \\
0.294 & 0.375 & 0.331 & 0 & 0 \\
0.351 & 0.402 & 0.247 & 0 & 0
\end{array}\right] \\
& =\left[\begin{array}{lllll}
0.3435 & 0.3930 & 0.2592 & 0.004 & 0
\end{array}\right] \\
& B_{4}=W_{4} \cdot R_{4}=\left[\begin{array}{lll}
0.296 & 0.371 & 0.333
\end{array}\right]\left[\begin{array}{ccccc}
0.360 & 0.386 & 0.254 & 0 & 0 \\
0.295 & 0.370 & 0.335 & 0 & 0 \\
0.401 & 0.378 & 0.221 & 0 & 0
\end{array}\right] \\
& =\left[\begin{array}{lllll}
0.3495 & 0.3774 & 0.2731 & 0 & 0
\end{array}\right] \\
& B=W \cdot R=\left[\begin{array}{llll}
0.175 & 0.3125 & 0.275 & 0.2375
\end{array}\right]
\end{aligned}
$$




$$
\left[\begin{array}{ccccc}
0.3294 & 0.4046 & 0.2660 & 0 & 0 \\
0.3153 & 0.3758 & 0.3005 & 0.007 & 0 \\
0.3435 & 0.3930 & 0.2592 & 0.004 & 0 \\
0.3495 & 0.3774 & 0.2731 & 0 & 0
\end{array}\right]=\left[\begin{array}{lllll}
0.334 & 0.386 & 0.277 & 0.003 & 0
\end{array}\right]
$$

\subsection{Calculate Comprehensive Evaluation Value}

$$
Z^{(1)}=B^{(1)} \bullet V^{T}=\left[\begin{array}{lllll}
0.334 & 0.386 & 0.277 & 0.003 & 0
\end{array}\right]\left[\begin{array}{lllll}
9 & 7 & 5 & 3 & 1
\end{array}\right]^{T}==7.102
$$

According to the comprehensive evaluation value, the $\mathrm{M}$ train gets 7.102 score. It indicate that $\mathrm{M}$ train's comprehensive benefit is more than middle-level.

\section{Conclusion}

In conclusion, China's High Speed Railway has gradually become the main and important mode of transportation in railway enterprise. Under the background, the objects of opening and operation of high speed railway is pursuit of maximum comprehensive benefits, which including social benefits, economic benefits and market benefits. Based on the three parts benefits, the article establishes a comprehensive evaluation indexes system and to further set an example to verify it taking the FAHP (Fuzzy Analytic Hierarchy Process) Calculation Model, it proves that comprehensive evaluation indexes system is reliable and feasible and high speed railway train should pursue comprehensive benefits. For this purpose, some effective measures to improve comprehensive benefits of CRH should be taken. Optimizing the opening plan of CRH, Improving transportation revenues based on flexible pricing strategy, strengthen costs control, actively expanding the market and improving service quality, which are all effective measures [6].

\section{References}

[1] Li, H.L. (2012) Study on Passenger Train Plan of High-Speed Railway. Beijing Jiaotong University, Beijing, 6: 36-39.

[2] Jiang, H.R. (2013) Study on Opening Benefits of CRH. China Chief Financial Officer, 10, 103-105.

[3] Zhang, X.X. (2011) Evaluation of High-Speed Railway Passenger Train Service Plan and System Development. Beijing Jiaotong University, Beijing, 6: 14-22.

[4] Yu, H.L. (2009) Study on Evaluating of Passenger Running Plan. Beijing Jiaotong University, Beijing, 6, 37-38.

[5] Song, W. (2009) Study on Performance of Running Railway Passenger Trains. Railway Transport and Economy, 1, 16-19.

[6] Du, D., Peng, Q.H. and Wu, Y. (2008) Modern Comprehensive Evaluation Method and Classic Cases. Tsinghua University Press, Beijing, 6: 100-112. 